\section{O mercado dos pobres: um enfoque qualitativo da utilização de programas sociais de alimentação}

\author{
A qualitative approach to nutritional \\ programs for low-income populations
}

Kátia Yumi Uchimura 1

Maria Lúcia Magalhães Bosi 2

\footnotetext{
1 Faculdade Evangélica do Paraná, Curitiba, Brasil.

2 Núcleo de Estudos em Saúde Coletiva, Universidade Federal do Rio de Janeiro, Rio de Janeiro, Brasil.

Correspondência Kátia Yumi Uchimura Rua Padre Anchieta 1944, apto. 191, Curitiba,PR 80730-000, Brasil. katyumi@terra.com.br
}

\section{Abstract}

This paper, based on a qualitative social research methodology, aims to analyze two nutritional programs through the users' perceptions. The study population consisted of frequent versus infrequent users of the program to identify similarities and differences and grasp various perspectives towards the phenomenon. Two main themes appeared in the discourse analysis: "routine functioning (of the program)" and "program user status". These themes gave rise to different categories demonstrating an association between the respective programs and poverty, as well as feelings related to this status, such as resignation, humiliation, and embarrassment. The study highlights the need to consider subjective aspects that influence social experiences and provide the basis for individual uniqueness, so that an effective dialogue between government planners and the population can be achieved.

Feed; Qualitative Research; Social Conditions; Government Programs

\section{Introdução}

Esta investigação trata da análise de dois programas desenvolvidos no Município de Curitiba, Paraná, Brasil - Mercadão Popular e Armazém da Família - no âmbito da política setorial, confrontando-os com as percepções de seus usuários.

Criado em 1986 com a proposta de comercializar, a preços mais acessíveis que aqueles praticados no mercado convencional, gêneros alimentícios junto à população com renda familiar inferior a três salários mínimos 1, o Mercadão Popular é operacionalizado a partir do deslocamento de ônibus adaptados à exposição e comercialização de alimentos, atendendo atualmente, com periodicidade quinzenal, a 67 pontos da periferia do município e sete da Região Metropolitana de Curitiba, Paraná. Já o Armazém da Família, versão mais recente da proposta anterior, compreende 17 unidades fixas de comercialização, localizadas em pontos estratégicos da cidade. Os dois programas representam diferentes formas de operacionalização de uma mesma proposta de intervenção, destinada a comercializar produtos alimentícios e produtos de higiene e limpeza à população de baixa renda residente no Município de Curitiba.

O acesso do usuário está condicionado a um cadastramento, realizado por organizações populares e, para tanto, é preciso que as famílias interessadas apresentem documento de 
identificação dos responsáveis, comprovação de renda familiar e comprovação de endereço. De posse da "carteirinha" de usuário, o indivíduo passa a ter acesso aos equipamentos de comercialização - respeitando-se o limite máximo de compras ao mês em cada equipamento.

Já situando tais ações no âmbito das políticas sociais, parece-nos importante percorrer alguns aspectos do debate teórico acerca desta temática, colocando em relevo a modalidade de intervenção sob análise e sua articulação com a noção contemporânea de cidadania.

Demo ${ }^{2}$ assinala que as políticas de alimentação e nutrição estariam teoricamente inseridas na categoria das políticas sócio-econômicas, devido à sua natureza voltada ao enfrentamento da pobreza material, que limita, a um grande contingente populacional, a satisfação das necessidades alimentares e nutricionais tanto no aspecto quantitativo como qualitativo.

No entanto, reportando-se à trajetória da política setorial, evidencia-se a elevada concentração das ações em modelos de intervenção desenvolvidos para a distribuição de alimentos a diversos segmentos, para o enriquecimento ou fortificação de alimentos e para a educação alimentar como forma de racionalizar e otimizar o consumo alimentar da população de baixa renda. Nesses casos, considerando-se o distanciamento existente entre os efeitos dessas ações e a possibilidade de superação das dificuldades materiais de seus destinatários, observa-se sua degeneração no sentido de uma conformação assistencialista 2 .

Tomando por base o modelo de intervenção dos programas abordados neste estudo, percebemos que esses guardam características que os diferenciam daquelas ações tradicionalmente desenvolvidas em âmbito federal. Ao contrário das ações mencionadas anteriormente, ambos são passíveis de enquadramento na categoria de políticas sócio-econômicas, considerando seu modelo de intervenção fundado na facilitação do acesso por meio de preços subsidiados, que representa um incremento direto no poder de compra, sem, contudo, imprimir de maneira tão explícita o estigma da pobreza à sua população beneficiária, como o fazem as ações de doação. Lavinas et al. 3 também reconhecem que determinadas modalidades de programas, entre elas as ações de comercialização de alimentos a preços subsidiados, apresentam caráter estrutural, que as diferenciam das ações de distribuição, de caráter emergencial e assistencialista.
Analisados sob o prisma tradicional da $\mathrm{ci}$ dadania, que prevê a igualdade e a universalidade de direitos e, por conseguinte, de acesso a bens e serviços básicos para todos os indivíduos de uma sociedade, os programas em foco cumprem seu papel como mecanismos compensatórios das desigualdades materiais existentes entre diferentes segmentos sociais. Além disso, permitem uma aproximação maior da perspectiva de satisfação sistemática e permanente das necessidades nutricionais dos grupos mais pobres, especialmente quando comparados às iniciativas que os antecedem, sem contar ainda que os preços de alimentos praticados nas regiões Sul e Sudeste, caso de Curitiba, apresentam-se relativamente mais altos que nas demais capitais, o que dificultaria sobremaneira o acesso da população de baixa renda 4 .

Maluf 5, em função do caráter essencial assumido pelas políticas compensatórias dirigidas ao combate às carências alimentares e nutricionais na sociedade capitalista, desenvolveu uma compreensão sobre estas ações e programas que tangencia a discussão proposta por Demo ${ }^{2}$. Assim, o autor destaca que as ações e os programas alimentares de natureza compensatória são portadores de três elementos: (a) educativos, em relação aos hábitos e práticas alimentares; (b) organizativos, para a defesa dos direitos de cidadania; (c) emancipadores, visando a promover a autonomia e não a dependência dos beneficiários.

Não obstante, se por um lado, os programas Mercadão Popular e Armazém da Família contribuem para o atendimento dos direitos fundamentais da população - incluindo o direito de acesso à alimentação adequada - implícitos na concepção tradicional de cidadania, consideramos igualmente relevante que tais ações vislumbrem em seu horizonte o atendimento da concepção contemporânea de cidadania 6 . Isso significa respeitar não apenas o aspecto material do direito, mas também os aspectos qualitativos que se inscrevem na subjetividade e que se manifestam nas particularidades e nas diferenças constitutivas dos alicerces da personalidade, da autonomia e da liberdade dos sujeitos, exercendo, portanto, um papel fundamental no desempenho dos programas sociais.

Nesse sentido, entendemos como premente o resgate das percepções dos atores e, principalmente, dos usuários, na análise de programas e serviços, pois a dimensão subjetiva implícita na noção de qualidade nos remete a um 
território que merece um maior aprofundamento. Nesse contexto, cabe assinalar as potencialidades de se utilizar uma estratégia que permita a apreensão dos sentidos dos fenômenos, e, ao mesmo tempo, respeite sua complexidade, riqueza e profundidade. Assim, esta investigação procura se alicerçar em uma postura de busca do sentido dos fenômenos no espaço da intersubjetividade, ou melhor, no espaço do encontro entre a subjetividade que se inscreve na vivência dos informantes - usuários - e na vivência do próprio pesquisador, por meio das compreensões e interpretações compartilhadas.

\section{Percurso metodológico}

Este estudo foi desenvolvido junto aos usuários cadastrados nos dois programas aqui focalizados, residentes nas áreas adjacentes ao $\mathrm{Ar}$ mazém da Família Santa Efigênia e aos pontos de Mercadão Popular Vila Leonice, Cachoeira e Abranches, no Município de Curitiba, Paraná. Essa região do município constituiu o espaço escolhido para o desenvolvimento da pesquisa pelo fato de comportar o primeiro e, portanto, mais antigo ponto de atendimento do programa, inaugurado em 1986.

A escolha da abordagem qualitativa para a realização deste estudo se justifica, em primeira instância, pela própria natureza do objeto, que supõe respostas múltiplas, as quais não podem ser expressas ou traduzidas por linguagem numérica (Fraenkel \& Wallen, 1990, apud Creswell 7).

Foram considerados em separado os usuários freqüentes (aqueles que se utilizam dos programas com freqüência mensal ou quinzenal) e os usuários não-freqüentes (aqueles cadastrados que não se utilizam dos programas ou o fazem apenas esporadicamente, com intervalo de dois meses ou mais entre cada visita), no sentido de evidenciar semelhanças e diferenças e, desta forma, permitir a apreensão de diferentes perspectivas diante do fenômeno a ser investigado. $\mathrm{O}$ critério para a seleção dos entrevistados levou em conta, portanto, o fato de a pessoa ser cadastrada nos programas.

A amostra não foi definida aleatoriamente; ao contrário, ela foi se constituindo com base em uma perspectiva de intencionalidade, como sugere Triviños 8, e compreendeu seis usuários freqüentes e sete não-freqüentes, os quais atendiam - tanto na totalidade, como na singularidade - os requisitos necessários para compor o conjunto de informantes-chave da investigação, considerando-se sua vivência indi- vidual frente os programas, somada à nossa expectativa em relação ao grau de profundidade que se pretendia alcançar nos depoimentos.

Para apreensão dos dados empíricos foram realizadas entrevistas em profundidade, com conteúdo registrado em fitas cassete após o consentimento dos informantes, transcrito em momento posterior.

Na seqüência, procedemos a leitura exaustiva e repetida do material, ou, como afirmam Minayo 9 e Triviñios 8, a leitura flutuante das transcrições das entrevistas, de maneira a permitir a nossa impregnação pelo sentido do "todo" de cada depoimento, bem como a identificação das unidades de significação, que indicam os vários "momentos" ou temas presentes nessas descrições 10 .

\section{Um enfoque vivencial da utilização \\ de programas sociais de alimentação}

A fase de análise, de acordo com Gomes 11, compreende o processo de interpretação dos dados. O termo processo sugere a existência de um movimento contínuo - que pode principiar já na fase de coleta do material - no sentido de se "olhar atentamente para os dados da pesqui$s a " 11$ (p. 68). Com efeito, durante as entrevistas, antes mesmo da transcrição do material, teria início o nosso envolvimento com o conteúdo das falas e, de forma ainda incipiente, daríamos os primeiros passos na direção do desvelamento de sentidos, assumindo, assim, conforme assinala Andrade 12 (p. 100), “...os aspectos intersubjetivos da dialogicidade inerente ao método".

Dois temas centrais emergiram dos depoimentos a partir da leitura e releitura das falas. São eles: o cotidiano do funcionamento e a condição de "ser usuário". Esses temas constituem os eixos centrais de nossa análise. Procuramos, na medida do possível, desdobrar cada tema em dimensões, as quais explicitam a reiteração das categorias empíricas nas falas dos entrevistados.

\section{- O cotidiano do funcionamento}

Na análise deste tema, ainda que se nos imponha a predominância de elementos de ordem formal ou objetiva, percebemos a possibilidade de seu desdobramento em dimensões intrínsecas às vivências individuais dos usuários junto aos programas. As dimensões referentes a este tema são: a ambiência e estrutura de apoio; a normatização do acesso e os preços e a qualidade dos produtos. Cabe assinalar que esse primeiro plano de entendimento dos pro- 
gramas poderia ser explorado por uma metodologia de caráter mais diretivo, utilizando-se de instrumentos mais estruturados. Contudo, a maneira pela qual esta expressão formal se articula com os sentimentos terminaria ocultada.

Embora alguns aspectos referentes ao funcionamento dos programas Mercadão Popular e Armazém da Família já tenham sido apresentados em momento anterior, os depoimentos dos entrevistados nos permitem um aproximação maior do cotidiano de sua utilização, revelando traços e percepções que são captados unicamente com base na análise de suas experiências singulares.

Um dos primeiros elementos que emergem das falas dos usuários refere-se à ambiência e à estrutura de apoio destinada à operacionalização dos programas. Segundo os entrevistados, o reduzido espaço físico destinado à circulação de pessoas nos ônibus do Mercadão Popular e nas edificações destinadas a abrigar os equipamentos do programa Armazém da Família penaliza os usuários pela acentuada situação de desconforto ocasionada ora pelo calor, ora pela necessidade de se aguardar a vez em longas filas sujeitas às variações climáticas, ou pela superlotação. Esse pensamento é compartilhado por usuários freqüentes e não-freqüentes.

“...Às vezes eu chego lá e tenho que ficar esperando porque tá entupido de gente. Lá (é um) mercadinho. Tem que ficar esperando porque não tem aquele conforto de um mercado normal.Claro que ali é o necessário mesmo, então não investem muito. No tamanho, né? (...) Então a gente fica aguardando!..." (Entrevistado 3 - usuário freqüente).

“...Começou a chover na época em que a gente tava lá, daí tinha que ficar na fila! Quem não podia ficar na chuva, com criança, foi embora! Acabou perdendo a vez e daí, só nos outros quinze dias que iam vir" (Entrevistado 1 usuário não-freqüente).

Já as percepções acerca da variedade dos produtos disponíveis na pauta de comercialização nos mostram diferentes possibilidades de interpretação da questão.

Especialmente entre os usuários não-freqüentes, evidencia-se o descontentamento em relação à diversificação da pauta. Tal insatisfação expressa o sentimento diante de uma situação que representa, para essas pessoas, uma restrição à liberdade individual de escolha.

“... O que você ganha numa chapa, perde numa foice. A metade das coisas não tem" (Entrevistado 7 - usuário não-freqüente).

Vista por outro ângulo, a limitada variedade pode se apresentar como um aspecto positivamente valorado, por contribuir indireta- mente para o uso racional dos parcos recursos disponíveis. Para vencimentos utilizados, quase na totalidade, no atendimento das demandas de consumo alimentar, a pequena variedade de produtos e de marcas, embora represente uma restrição do espectro de opções, parece exercer efeito facilitador no processo de seleção dos alimentos a serem adquiridos. De acordo com esse raciocínio, sem a tentação ao alcance dos olhos, seria provavelmente menos difícil controlar o desejo de consumir além das possibilidades do orçamento.

“...No Armazém não tem muitas marcas diferentes. (Isto) ajuda porque daí você não tem muita opção pra gastar...(Em outro supermercado) eu acho mais difícil porque a gente sempre fica em dúvida" (Entrevistado 4 - usuário freqüente).

Porém, deixar de comprar um determinado produto por não sentir vontade de consumi-lo ou por não dispor de condição financeira momentânea para adquiri-lo, difere substancialmente do fato de deixar de comprar um produto porque o mesmo nunca se encontra disponível para a venda no equipamento social.

“...Sou cardíaco e sou diabético. Eu não posso comer margarina com sal (...) e margarina não tem (de) outro tipo pra vender. Só aquele tipo (...) com sal. Então você não tem o que escolher! Chega ali tem que comprar o que tem ..." (Entrevistado 7 - usuário não-freqüente).

Esse impasse entre o querer e o poder remete-nos ao que Bobbio 13 (p. 49), denomina " $l i$ berdade negativa" e "liberdade positiva". Essas duas formas de liberdade identificadas pelo autor derivariam, segundo nosso entendimento, da concepção filosófica aristotélica de liberdade. A liberdade negativa estaria associada à "ausência de impedimento ou de constrangimento", ou seja, à possibilidade de fazer algo sem ser impedido ou de não ser obrigado ou constrangido a fazer algo. Já a liberdade positiva, também conhecida por "autodeterminação" ou "autonomia”, significaria a possibilidade de o sujeito “...orientar seu próprio querer no sentido de uma finalidade, de tomar decisões, sem ser determinado pelo querer de outros" 13 (p. 49).

Assim, ao limitar as possibilidades de escolha, os programas estariam estabelecendo limites à liberdade de querer, levando, invariavelmente, a uma predefinição da decisão por comprar ou deixar de comprar determinado produto e, na concepção dos entrevistados não freqüentes, essa situação levaria à imposição, sutil e silenciosa, dos produtos passíveis de inclusão em seu universo de consumo.

A dimensão "A normatização do acesso" refere-se ao conjunto das normas que regulam os 
aspectos operacionais determinantes das condições de atendimento aos usuários nos vários pontos de venda.

As referidas normas encontram-se expostas na entrada do Armazém da Família Santa Efigênia e, de imediato, é possível perceber a elevada concentração de mensagens - as "regras" - impondo algum tipo de restrição: (a) apresente a carteirinha e documento com foto do usuário que fará as compras; (b) observe o limite de cotas permitidas; (c) cheques e tíquetes não serão aceitos; (d) solicite ao caixa para controlar o valor de sua compra, evitando devoluções; (e) se possível, traga dinheiro trocado; (f) confira sempre seu troco; (g) embalagens não são fornecidas; (h) trocas somente com a apresentação de ticket do caixa; (i) carrinhos e cestinhas não podem sair do interior do Armazém; (j) para sua comodidade, evite trazer acompanhantes; (k) para evitar acidentes, recomendamos não entrar com crianças.

Um elemento regulador merece destaque: o limite de produtos permitido em cada compra, ou seja, a cota de produtos.

As opiniões quanto ao estabelecimento de uma cota máxima para determinados produtos são divergentes entre os usuários freqüentes e não-freqüentes. Entre os usuários freqüentes, a existência das cotas parece ser um fato naturalmente aceito:

"Que nem tem pessoas que falam:-Ah, eu não vou mais no Mercadão porque tem uma cota pra comprar. Mas tá certo ter uma cota porque você veja: por mais que seja uma família grande, não precisa comprar mais do que cinco pacotes de arroz..." (Entrevistado 13 - usuário freqüente)

Partindo da afirmação do usuário, que diz não ser necessária uma quantidade tão grande para a satisfação das necessidades de uma família numerosa, empreendemos uma análise da composição química dos produtos incluídos na cota, com o intuito de verificarmos o grau de atendimento das recomendações nutricionais, e constatamos que a existência de um limite não impede o atendimento dos requerimentos nutricionais de energia e proteínas estabelecidas pelo National Research Council em 1989 14, uma vez que o consumo de toda a quantidade considerada em nosso cálculo ultrapassaria em $89,11 \%$ as necessidades de proteína e em $38,4 \%$ as de energia.

No entanto, observamos em depoimentos de usuários não-freqüentes, que a existência das cotas representaria um problema.

“...Você tem o limite de compra, esse que éo problema. Você tem o limite pra poder comprar" (Entrevistado 1 - usuário não-freqüente).
É possível perceber que, embora esse limite não implique a impossibilidade de satisfação de suas necessidades nutricionais, sua simples existência representaria a imposição de um padrão quantitativo de consumo. Vale acrescentar que as necessidades dos indivíduos não se restringem àquelas de ordem biológica. Exis tem necessidades de natureza simbólica, cujo valor se iguala ou até mesmo supera as necessidades de natureza orgânica ou fisiológica 15 .

No conjunto, as regras há pouco referidas parecem estar muito presentes na memória dos usuários, em função, talvez, da cobrança no sentido de cumpri-las que se impõe a cada situação vivida junto aos programas, adquirindo, nessa perspectiva, uma existência concreta: "tem uma porção de regras. Isso aí o moço falou pra mim na hora em que tive que mostrar a carteirinha, (...) ali na porta. Ele falou que tem as regras: (o) tanto que compra, de pessoas lá. Está escrito tipo: óleo, tantas latas, tantas compras no mês. Tem muitas regras. Então você tá pagando pra seguir regras. Eu não aceito, sinceridade. É meio difícil" (Entrevistado 5 - usuário não-freqüente).

Outra dimensão explorada neste tema foi “O preço e a qualidade de produtos", uma vez que o preço acessível é considerado um ponto forte dos programas, infalivelmente anunciado nos documentos e materiais de divulgação concernentes às ações desenvolvidas pela Secretaria Municipal de Abastecimento (SMAB). A menção que se faz à diferença entre os preços praticados nos programas e aqueles praticados no comércio em geral pode ser observada em diferentes momentos, sendo que, em alguns deles, esse valor aparece objetivamente dimensionado - $30 \%$ em média 16,17 .

Nas falas de usuários freqüentes, evidenciase a importância do aspecto econômico: “...qualquer coisinha a menos, a pessoa já ganha o freguês. Porque, uma comparação: você vai comprar, vamos supor aí, cinqüenta reais de mercadoria. (...) comprando lá no mercado, uma lata de óleo custa o quê? Um real e pouco. Aqui, tá oitenta e quatro (centavos)! Quer dizer que, por aí, a gente já tira que se ele comprar (...) cinco latas de óleo (...) ele já vai ganhar uma quantidadezinha. Já dá pra comprar outra lata" (Entrevistado 11 - usuário freqüente).

Sentimos a necessidade de verificar essa diferença de preço no sentido de articular, na análise, o plano subjetivo com a objetividade à qual ele se reporta. Para tanto, comparamos os preços praticados nos programas com os preços dos mesmos produtos em outros supermercados de Curitiba, por intermédio de um serviço disponibilizado pela SMAB - Disque 
Economia - que fornece, via Internet ou ligação telefônica, informação atualizada sobre preços de produtos em vários supermercados da cidade. Neste caso, fizemos a consulta por meio da home page da Prefeitura Municipal de Curitiba 18, e pudemos constatar que o valor da compra do conjunto dos itens pesquisados em três supermercados excederia o valor da mesma compra nos programas Mercadão Popular e Armazém da Família. Nessa semana específica, os preços praticados nos supermercados mostraram-se, em média, superiores aos dos programas em $33,79 \%$; ratificando, portanto, o valor usualmente divulgado pela SMAB.

Os depoimentos de usuários freqüentes se confirmam ante a realidade concreta: os preços dos produtos são realmente atrativos. No entanto, deparamo-nos, na fala dos usuários não-freqüentes, com um elemento aparentemente indissociável na avaliação do beneficio ou ganho econômico advindo da aquisição de produtos com preços mais acessíveis: a qualidade - no âmbito deste aspecto específico circunscrita aos atributos físicos e sensoriais dos produtos comercializados. Para eles, o preço reduzido não constituiria um motivo suficientemente compensador para adquirir produtos cujos atributos estivessem dissonantes de suas expectativas.

“...Ainda falam que as coisas são muito baratinhas. Mas muito inferiores! Pra mim, são inferiores. Não adianta comprar uma coisa mais barata que num mercado e ser ruim. (...) Eu ando mais um pouco, mas compro uma coisa melhor..." (Entrevistado 06 - usuário nãofreqüente).

“Ih! Eu achei que não é tanta vantagem nos preços. Pela qualidade (que) deixa muito a desejar" (Entrevistado 5 - usuário não-freqüente).

Esta percepção sobre os atributos dos produtos pode ser reveladora da associação que se faz entre a utilização dos programas e uma situação de sujeição. Essa suposição nos levaria a pensar que o uso freqüente dos programas seria determinado unicamente pela necessidade econômica, cuja influência na freqüência de utilização estaria se sobrepondo às demais possibilidades, incluídos os elementos subjetivos responsáveis pela identificação do usuário com a proposta:

De fato, embora os programas Mercadão Popular e Armazém da Família tenham conseguido manter preços reduzidos quando comparados aos preços praticados nos estabelecimentos convencionais, não podemos - apoiados exclusivamente no aspecto econômico sustentar a afirmação de que sua utilização seja vantajosa. Se, por um lado os depoimentos dos usuários freqüentes nos revelam sua preocupação para com o aspecto econômico da aquisição de alimentos, faz-se igualmente importante refletirmos sobre os depoimentos de usuários não-freqüentes, pois estes nos sugerem a existência de outros elementos que podem se contrapor àqueles de ordem material ou econômica na determinação da freqüência de utilização ou na própria decisão pela utilização de urna intervenção governamental.

\section{- A condição de "ser usuário"}

Neste tema, nosso foco passa a contemplar a “experiência vivida" 19 dos usuários junto aos programas, ou seja, a forma pela qual os sujeitos experimentam e vivenciam as circunstâncias, sejam estas adversas ou não, inerentes ao fato de ser beneficiário de um programa social para obter aqueles bens necessários ao sustento da família.

Um ponto se mostra bastante claro, tanto para usuários freqüentes como para não-freqüentes: a quem se destinam tais programas e qual o significado de se pertencer a tal grupo. Em seus depoimentos, categorias como inferior, nível baixo, pobres e mais humilde emergem com certa recorrência na identificação do público alvo dessa ação governamental específica: “...então eu vejo nesse sentido, que tem aquelas pessoas mais inferiores. Daí eles vão ali, porque ali é onde eles podem comprar, porque tá ao alcance deles. É assim que eu vejo" (Entrevistado 11 - usuário freqüente).

“Ah, o Mercadão (...) eu acho que a pessoa que fez já pensou na pessoa assim, que não tem condições de ir num mercado, não compra. Pra mim, o Mercadão é uma coisa assim: eu digo que é o mercado dos pobres..." (Entrevistado 8 - usuário não-freqüente).

“...esse mercado é da pobreza, isso é o mercado da pobreza..." (Entrevistado 11 - usuário freqüente).

“E a gente vê que a maioria das pessoas são diaristas, são pedreiros,desempregados, pessoas que é a parte pobre mesmo que procura. Pessoas mais abastadas não procuram" (Entrevistado 3 - usuário freqüente).

"Só pessoas que não podem comprar: pessoas do nível baixo. Só as pessoas do nível baixo" (Entrevistado 10 - usuário não-freqüente).

Percebemos que a pobreza e o pobre, especificamente, aparecem, segundo as categorias presentes nas narrativas, associados a uma noção de inferioridade e subordinação. Essa situação repercutiria, por sua vez, em uma necessidade de sujeição diante do que se tem acesso. Essa constatação emerge de forma ex- 
plícita das verbalizações de usuários não freqüentes: “...quem não tem escolha traz a margarina salgada mesmo. E aquele café deles lá, horrivel de ruim, mas quem não tem cachorro, caça com gato mesmo. De que jeito? E vai vivendo, né?" (Entrevistado 7 - usuário não-freqüente).

“...O arroz não é um arroz de primeira assim, sabe? Mas é um arroz que todo mundo pode comer dele, na classe de pobre é claro que a gente pode comer. Então é um arroz bom e tá bem mais em conta que nos mercados" (Entrevistado 10 - usuário não-freqüente).

Observamos que a utilização dos programas abordados neste estudo configuraria uma espécie de resignação imposta pela precariedade das condições materiais de existência, ou de sobrevivência. Tanto que, a despeito da possibilidade de economia, a utilização freqüente dos programas - na percepção dos usuários que desistiram de sua utilização ou os utilizam apenas esporadicamente - parece estar reservada como estratégia para aqueles que convivem com a impossibilidade de acesso a outros estabelecimentos: "bom, se a gente tivesse bastante dinheiro, não faria compra lá! Porque lá é pra pessoas de baixa renda. Pras pessoas que não ganham muito. Porque as pessoas que ganham bem vão no melhor mercado! Vão nesses aí comprar melhor, né?" (Entrevistado 1 - usuário não-freqüente).

“Agora, vantagem tem pros pobres, pros coitados que não têm condições de ir num mercado lá, que nem vocês vão. E enchem dois, três carrinhos. Deus que abençoe quem pode fazer isso!"'(Entrevistado 8 - usuário não-freqüente).

Diante de relatos que evocam uma suposta inferioridade - que por seu turno remete à necessidade de sujeição e resignação - parece-nos importante compreender a lógica de construção da identidade social do pobre. Segundo Sarti 20, a imagem histórica do pobre encerra em si uma negatividade, por ele representar a ausência, o avesso daquilo que deveria ter ou ser. Se inicialmente estava associado apenas à ausência ou carência material, hoje o pobre personificaria igualmente a ausência de direitos.

A identidade social é definida e só tem sentido a partir de contrastes. Assim, a categoria pobre aparece em oposição à categoria rico 20 . Essa dicotomia rico $\mathrm{x}$ pobre também é identificada por Caldeira 21 e Salem 22, na explicação dos sujeitos para sua situação social e para o lugar por eles ocupado no mundo. O "ser rico" ou o "ser pobre" determinaria quem são os “iguais" e quem são os “outros”.

Por esse ângulo, podemos supor que, nas representações da população usuária dos pro- gramas, a vida reservada aos pobres não só pode como deve ser diferenciada - implícita a noção de inferioridade - da vida destinada aos ricos, daí a aceitação de situações usualmente não toleradas pelos sujeitos de maior poder aquisitivo. Para pobres e ricos, a noção do que é bom ou ruim também obedeceria a critérios diferenciados.

Entendemos que os depoimentos, ao se referirem aos programas como bons para os $p o$ bres, procuram demonstrar, nas entrelinhas, que os programas são bons apenas para os pobres, para aqueles que estabelecem uma relação de dependência para com tais ações governamentais, tendo em vista que os ricos, representando o grupo que não depende dos programas, estando isentos da sujeição inerente à utilização dos mesmos.

Nessa perspectiva, a utilização dos programas não apenas reforçaria o estigma da pobreza, mas contribuiria para identificar, conforme a assiduidade, aqueles mais pobres, ou seja, aqueles sujeitos que, inevitavelmente, buscam nesses mecanismos um apoio à sua sobrevivência.

São várias as categorias experienciais que retratam os sentimentos dos usuários no seu vivido junto aos programas. A ambigüidade vinculada à freqüência de utilização dos mesmos, pontuada anteriormente em diversos momentos, parece diluir-se ante a profundidade das revelações. Observamos a presença de categorias como decepção, constrangimento, tristeza, sofrimento, humilhação, desamparo, discriminação.

"Ah, me senti humilhada! Bem humilhada. (...) eu sinto que todas as pessoas que estão ali sentem-se humilhadas" (Entrevistado 5 - usuário não-freqüente).

"Ah, eu sei lá. Eu fiquei assim decepcionada. Isso daí foi uma decepção. Daí você já fica assim meio perdida porque não sabe como funciona. (...) Não te dão a mínima, parece que você é uma coisa qualquer, sei lá. Não me serve isso" (Entrevistado 5 - usuário não-freqüente).

“...Então a pessoa se sente assim ... triste, constrangido porque não tem tanta energia assim pra se movimentar, né?...” (Entrevistado 4 usuário freqüente).

“...Mas faz a gente se sentir diferente porque nos outros armazéns, nos outros mercados, a gente pode levar o carrinho. (...) Então essas coisas deixam a gente meio... assim encabulado, sei lá, por causa disso. Porque a gente não pode usar esse tipo de coisa" (Entrevistado 4 - usuário freqüente).

Os depoimentos também nos permitem vislumbrar como se dá esse processo de aceita- 
ção ou negação dos programas por parte dos usuários e quais motivos são desencadeadores das diversas posturas, desde a utilização regular ou a utilização esporádica até o abandono dos programas.

Entre os usuários freqüentes, o preço dos produtos destaca-se entre os motivos que remetem à utilização regular, sistemática e freqüente dos programas, ratificando nossa concepção acerca da importância desse aspecto na determinação da freqüência de utilização.

“No Mercadão, eu vejo assim, economia.(...) Dá essa diferença (...). Eu, quando fuço compra no Mercadão, vejo que meu dinheiro rende. Quando eu vou no mercado normal, eu gasto mais, às vezes, além do que precisava gastar" (Entrevistado 3 - usuário freqüente).

"Por causa do salário (...), as coisas são mais em conta, mais baratas. Facilita mais (...). A diferença é enorme, né?..." (Entrevistado 2 - usuário freqüente).

Já os usuários não-freqüentes, muitos dos quais admitem-se como desistentes, ainda que portadores da carteira de cadastro, relatam motivos diversificados.

“...Eu dei uma parada agora porque o Mercadão é longe (...). Ultimamente eu parei porque é longe pra gente ir buscar as compras.Não tem com o que eu ir buscar. Não tenho carro, não tenho nada. Mas eu parei por causa disso daî" (Entrevistado 1 - usuário não-freqüente).

“...Eu quase não gostava de comprar no Mercadão por causa desse motivo. Eu compro bastante verdura e lá dentro não tem verdura! É só o arroz,feijão, café,açúcar, azeite, bolacha, essas coisas. Mas verdura é tudo ali fora" (Entrevistado 7 - usuário não-freqüente).

"Eu comprei uma vez, daí você não tem opção de marcas, até mesmo de qualidade (...). Tem farinha de trigo, vem daquela preta, escura. Aqui em casa a gente não usa. Biscoitos, você não tem variedade. Enfim, é tudo assim. Aí,acabei desistindo. Falei: - Não, não é por aí. A gente trabalha só pra comer, então, vamos comer uma comida decente, de marcas melhores. Que pague um pouco mais, porque já não faz mais nada na vida a não ser comer, né? Eu trabalho pra isso! Então é isso aî" (Entrevistado 5 - usuário não-freqüente).

“...Ah, nem sei. Nem eu, nem meu marido, nós não gostamos de ir ali. Não sei por que eu não gostei dali. A gente já é pobre. Sair pra comprar umas coisas mais inferiores ainda, o que não fica? (...) eu ando mais um pouco, mais longe,pra poder comprar coisas melhores" (Entrevistado 6 - usuário não-freqüente).

"Ah, sei lá. Porque o meu marido ele gosta mais do arroz melhor um pouquinho. Dai como a gente não come muito, a gente procura comprar do arroz melhor um pouquinho. E o arroz ali ele é bom, mas sempre que não souber fazer ele fica meio papa. Mas por isso eu não compro ali.Compro pouca coisa ali. Eu uso o Mercadão pouco..." (Entrevistado 10 - usuário não-freqüente).

Admitimos que a carga de objetivação presente nos relatos tem origem na forma como a informação foi obtida junto aos entrevistados. Não fosse a iniciativa de conduzir o usuário a uma racionalização da questão colocada, tais motivos poderiam emergir do interior de suas falas de forma espontânea, permitindo-nos acessar o fenômeno de maneira ainda mais aprofundada.

Quando o entrevistado refere não se sujeitar ao consumo de determinados produtos, mesmo sendo pobre, ele nos mostra uma vontade imanente e, talvez ainda não consciente, de libertação, de fazer escolhas, de exercício de cidadania, no sentido aqui empregado. A condição de pobreza parece ser assumida nos depoimentos dos usuários não-freqüentes, mas as situações de sujeição e inferioridade impostas por essa condição de pobreza não nos parece igualmente aceita.

Cabe analisar, também, o valor simbólico atribuído ao ato de consumir "uma comida decente", como nos relata o usuário. Sabemos que a comida, ou as comidas em geral, além dos nutrientes encerram igualmente uma carga de signos elaborados a partir do universo cultural dos sujeitos. Neste caso, o consumo de um produto com determinadas características poderia conferir aos sujeitos a inclusão em um ou outro grupo social.

DaMatta 15 (p. 57), afirma que " a comida vale tanto para indicar uma operação universal - o ato de alimentar-se - quanto para definir e marcar identidades pessoais e grupais, estilos regionais e nacionais de ser, fazer, estare viver". À comida é atribuída a tarefa de demarcar a identidade social dos sujeitos.

Para alguns, comprar a comida nos programas e comer a comida do "Mercado dos Pobres" pode representar a ratificação da sua necessidade de sujeição e, conseqüentemente, de sua suposta condição de inferioridade. Deixar de comprar ou não consumir tais produtos, em contraste, pode simbolizar um maior grau de proximidade para com outros estratos sociais. 


\section{Considerações finais}

Na análise dos programas Mercadão Popular e Armazém da Família, evidencia-se a influência de elementos qualitativos, impregnados de subjetividade, na gênese dos valores e, por conseguinte, na emissão do juízo empreendida por sua população usuária.

Embora tais programas encerrem elementos que, dada a especificidade de seu modelo de intervenção, subsidiam o enfrentamento das privações materiais comuns aos usuários, tal como a dificuldade de acesso aos alimentos necessários ao seu sustento, ainda assim não conseguem romper a distância que os separa do atendimento às expectativas dessa população e, nessa perspectiva, ao contrário do que se mostra com base em uma análise superficial, eles não confluem necessariamente para o que aqui entendemos por cidadania, em todas as suas dimensões constitutivas.

Como vimos, a utilização de uma intervenção dessa natureza, longe de corresponder a um mero auxílio material, está profundamente associada à afirmação da liberdade, da autonomia ou da falta delas e, principalmente, à definição de uma identidade social. Essa constatação se mostra ainda mais explícita valendo-se das percepções dos usuários não-freqüentes.

Em muitos momentos, destacamos as divergências presentes nas falas dos dois grupos - usuários freqüentes e usuários não-freqüentes - por entendermos que isso confirmaria as inúmeras possibilidades de leitura de uma mesma intervenção. Dessa forma, foi-nos possível elucidar a imbricação dos programas com a identidade da pobreza e os sentimentos inerentes à essa condição, tais como a resignação, a sujeição, a humilhação e o constrangimento, entre outros mencionados. Sentimentos esses que desempenham, junto aos usuários, um papel contundente na decisão pela utilização dos programas. Tão contundente a ponto de sobrepujar, em alguns casos, até mesmo a precariedade de suas condições de vida.

Seguramente, os setores responsáveis pela planificação e implantação de políticas sociais, ao se dissociarem do excesso de objetividade imposto pelo estabelecimento de objetivos operacionais e pela busca de resultados mensuráveis, experimentarão um verdadeiro diálogo junto ao público destinatário de suas intervenções. Isso, muito além de todas as inovações técnicas possíveis de serem aplicadas aos equipamentos sociais, requer um aprendizado quanto às necessidades legítimas da população, ou seja, um aprendizado em direção ao reconhecimento das necessidades assim percebidas pelos usuários, as quais não podem ser simplesmente traduzidas em números. Em outras palavras, há que se considerar a subjetividade que permeia as práticas sociais e que alicerça as singularidades dos sujeitos, pois, pelo que se observa, as falas da população não têm sido acessadas pelo seu interlocutor - o órgão gestor. Com efeito, as linguagens utilizadas são, ainda, muito diferentes.

\section{Resumo}

A presente investigação trata da análise de dois programas sociais na área de alimentação confrontandoos com as percepções de seus usuários. A orientação metodológica inscreve-se na abordagem qualitativa de pesquisa social, sendo a população estudada composta por usuários freqüentes e não-freqüentes, de modo a evidenciar semelhanças e diferenças e permitir a apreensão de diferentes perspectivas diante do fenômeno investigado. Dois temas centrais emergiram da análise discursiva: o cotidiano do funcionamento e a condição de "ser usuário". Esses temas, eixos centrais de nossa análise, desdobraram-se em distintas dimensões a partir das quais tornou-se possível elucidar a imbricação dos programas com a identidade da pobreza e com os sentimentos inerentes à essa condição, tais como: resignação, humilhação, sujeição e constrangimento. Os achados reforçam a necessidade de se considerar a subjetividade que permeia as práticas sociais e que alicerça as singularidades dos sujeitos para que, dessa forma, possa se estabelecer uma efetiva interlocução entre os setores responsáveis pela planificação e implantação de programas sociais e a população a que se destinam.

Alimentação; Pesquisa Qualitativa; Condições Sociais; Programas Governamentais 


\section{Colaboradores}

A idealização do artigo, a análise nele contida, o atendimento às sugestões dos revisores, a revisão do texto final, dentre outros pontos, foram desenvolvidos conjuntamente pela autoras.

\section{Referências}

1. Secretaria Municipal do Abastecimento. Políticas e diretrizes. Curitiba: Secretaria Municipal do Abastecimento; 1987.

2. Demo P. Política social, educação e cidadania. Campinas: Editora Papirus; 2000.

3. Lavinas L, Manão D, Garcia EH, Bittar M, Bahia M, Bezerra RA. Combinando compensatório e redistributivo: o desafio das políticas sociais no Brasil. Brasília: Instituto de Pesquisa Econômica Aplicada; 2000. (Texto para discussão 748).

4. Lavinas L. Acessibilidade alimentar e estabilização econômica no Brasil nos anos 90. Rio de Janeiro: Instituto de Pesquisa Econômica Aplicada; 1998. (Texto para discussão 591).

5. Maluf RS. Ações públicas de segurança alimentar para grupos populacionais específicos. R S Polis Paper 2000; 7. http://www.polis.org.br/publica coes/papers/20007.html (acessado em 05/Ago/ 2003).

6. Dagnino E. Os movimentos sociais e a emergência de uma nova cidadania. In: Dagnino E, organizador. Anos 90: política e sociedade no Brasil. São Paulo: Editora Brasiliense; 1994. p. 103-15.

7. Creswell JW. Research design: qualitative \& quantitative approaches. London: Sage Publications; 1994.

8. Triviños ANS. Introdução à pesquisa em ciências sociais: a pesquisa qualitativa em educação. São Paulo: Editora Atlas; 1987.

9. Minayo MCS. O desafio do conhecimento: pesquisa qualitativa em saúde. São Paulo: Editora Hucitec/Rio de Janeiro: ABRASCO; 1998.

10. Martins J, Bicudo MAV. A pesquisa qualitativa em psicologia: fundamentos e recursos básicos. São Paulo: EDUC-Editora; 1989.

11. Gomes R. A análise de dados em pesquisa qualitativa. In: Minayo MCS, organizadora. Pesquisa social: teoria, método e criatividade. Petrópolis: Editora Vozes; 1995. p. 67-80.

12. Andrade A. Para além dos sintomas: a trilogia do desamparo no vivido de mulheres com transtornos do comportamento alimentar [Dissertação de Mestrado]. Fortaleza: Faculdade de Medicina, Universidade Federal do Ceará; 2000.
13. Bobbio N. Igualdade e liberdade. Rio de Janeiro: Ediouro; 1997.

14. Mahan LK, Escott-Stump S. Krause: alimentos, nutrição \& dietoterapia. 9a Ed. São Paulo: Roca; 1998.

15. Da Matta R. O que faz o Brasil, Brasil? Rio de Janeiro: Editora Rocco; 1986.

16. Secretaria Municipal do Abastecimento. Diretrizes básicas. Curitiba: Secretaria Municipal do Abastecimento; 1989-1992.

17. Secretaria Municipal da Comunicação Social. Abastecimento: uma parceria vitoriosa com a população. Curitiba: Secretaria Municipal da Comunicação Social; 1995.

18. Prefeitura Municipal de Curitiba. Disque-Economia. http://www.curitiba.pr.gov.br/cgi-bin/disque economia. (acessado em 22/Mar/2003).

19. Solymos GMB. A experiência vivida de mães de desnutridos: um novo enfoque para intervenção em desnutrição infantil. In: Sawaya AL, organizador. Desnutrição urbana no Brasil em um período de transição. São Paulo: Editora Cortez; 1997. p. 127-53.

20. Sarti CA. Os pobres nas ciências sociais brasileiras. Campinas: Autores Associados; 1996.

21. Caldeira TPR. A política dos outros: o cotidiano dos moradores da periferia e o que pensam do poder e dos poderosos. São Paulo: Editora Brasiliense; 1984.

22. Salem T. Mulheres faveladas: "com a venda nos olhos". In: Franchetto B, Cavalcanti MLVC, Heilborn ML, organizadores. Perspectivas antropológicas da mulher 1. Rio de Janeiro: Editora Zahar; 1980. p. 49-99.

Recebido em 30/Dez/2002

Versão final reapresentada em 18/Ago/2003

Aprovado em 04/Set/2003 